\title{
Joint Attention and Attachment in Toddlers with Autism
}

\author{
Fabiënne B. A. Naber • Sophie H. N. Swinkels • \\ Jan K. Buitelaar • Claudine Dietz • Emma van Daalen • \\ Marian J. Bakermans-Kranenburg • \\ Marinus H. van IJzendoorn • Herman van Engeland
}

Published online: 5 June 2007

(C) Springer Science + Business Media, LLC 2007

\begin{abstract}
Joint attention is often referred to as a triadic relation between self, other and object. Young children with autism show deficiencies in the use of joint attention behaviors. Individual differences may be expected, and they may be determined by the children's cognitive development or the characteristics of the relationship of the child with the caregiver. Although most joint attention skills develop under the age of three, most studies of joint attention in children with autism involved children older than 3 years of age, due to difficulties in diagnosing autism under this age. In this study we investigated joint attention behaviors of 78 young children (mean age 25.7 months, SD 6.1) with autism spectrum disorders $(n=20)$, other developmental delays $(n=18)$, and typically developing children $(n=40)$. Following the pertinent literature and confirmed by factor analysis, two types of joint attention behaviors were distinguished, Basic Joint Attention (BJA) and Associated Joint Attention (AJA). We found that cognitive delays and autistic symptoms - but not attachment insecurity or disorganization - were related to less joint attention. Already at
\end{abstract}

F. B. A. Naber $(\bowtie) \cdot$ M. J. Bakermans-Kranenburg •

M. H. van IJzendoorn

Center for Child and Family Studies, Leiden University,

P. O. Box 9555, Leiden NL-2300RB, The Netherlands

e-mail: Fnaber@fsw.leidenuniv.nl

F. B. A. Naber $\cdot$ C. Dietz $\cdot$ E. van Daalen $\cdot$ H. van Engeland

Department of Child and Adolescent Psychiatry,

Rudolph Magnus Institute of Neuroscience,

University Medical Centre Utrecht,

Utrecht, The Netherlands

S. H. N. Swinkels $\cdot$ J. K. Buitelaar

Department of Psychiatry,

Radboud University Nijmegen Medical Centre,

Nijmegen, The Netherlands the age of 2 years, children with more autistic symptoms show less joint attention, even after controlling for developmental level.

Keywords Joint attention · Autistic disorder - Toddlers ·

Attachment

Joint attention is one of the core deficits of autism (Charman 2003; Sigman et al. 2004) and is now commonly used for early detection of autism. Only a few nonretrospective studies have focused on joint attention skills of children with autism spectrum disorders under age three, due to difficulties with diagnosing younger children. In the present study, joint attention is examined in infants with autism spectrum disorders, matched clinical control children, and age matched typically developing children. The aim of this study was to test whether the development of joint attention in children with ASD is deviant as early as age three or younger. We also investigated the association between the quality of the infant-parent attachment relationship and the child's joint attention skills.

Joint attention is often referred to as a triadic relation between self, other and object (Bakeman and Adamson 1984; Hobson 1993; Leekam et al. 2000), and indicates the earliest behavior of the infant's awareness of others' minds (Bretherton et al. 1981; Charman 1997; Stern 1985). Therefore, early joint attention behaviors are considered a major milestone in the development of a child (e.g., Bakeman and Adamson 1984; Mundy and Gomes 1997; Tomasello 1995). However, in common terminology 'joint attention' is not used for one single behavior, but for a cluster of behaviors. Many researchers who study typically developing infants consider a range of social cognitive skills to be 'joint attention' skills. Behaviors that are described as (related) joint attention, are: 'gaze following,' 
'pointing behavior,' 'mutual gazing' or 'joint visual attention,' 'follow pointing/look in point direction of speaker,' 'showing an object,' 'checking,' 'gestures,' 'taking,' 'giving' and 'response to name.' In short, a range of behaviors including another person and related to attention (dyadic and triadic) have been described as joint attention. With an eye to differences in constructs and terminology, Bruner (1995) noted that joint attention behavior should be clarified in terms of what it consists of, how it is achieved, and by what criteria it is judged.

\section{Development of Joint Attention and Attachment}

In typical development, joint attention behaviors emerge prelinguistically, between 6 and 12 months of age (Charman 2003), and involves interaction with others. Young infants' interactions are mainly with their mothers. The development of joint attention usually starts with 'pointing out objects to others' and 'checking others' gaze direction toward objects' (Carpenter et al. 2002; Leekam et al. 2000). These behaviors can be described as 'basic' joint attention behaviors (BJA). It has been argued that these joint attention behaviors are particularly related to the development of both expressive and receptive language (Charman 2003; Mundy et al. 1990; Goldsmith and Rogoff 1997). Other behaviors that are described as associated with joint attention are: 'follow pointing/look in point direction of speaker,' 'showing an object,' 'checking,' 'gestures,' 'taking,' 'giving' and 'response to name.' These behaviors develop after the earlier basic joint attention behaviors (Charman 2003; Mundy et al. 1990) and may be referred to as associated joint attention (AJA).

The association between joint attention and language has been described by several authors (a.o. Charman 2003; Mundy et al. 1990; Goldsmith and Rogoff 1997). To acquire language, the child has to understand the link between words and objects, and to interpret communicative gestures of others as intentional acts (Tager-Flusberg 2000). Autistic children's deficits in joint attention, i.e. deficits in understanding the meaning of gestures such as pointing and looking, may therefore be linked to delays in receptive language and overall language acquisition.

Although the association between attachment and joint attention has hardly been empirically examined, it has often been indicated that the tendency of an infant to engage in social interaction is affected by the quality of the infantparent relationship (Claussen et al. 2002; Flanagan et al. 1994; Goldsmith and Rogoff 1997; Raver and Leadbeater 1995; Ruff and Rothbart 1996; Scholmerich et al. 1997). Several authors have shown that parental processes affect the child's attention (Fearon and Belsky 2004; Ruff and Rothbart 1996). In an observational study Main (1983) found that 3-year-olds with a secure attachment show longer attention spans. De Wolff and Van IJzendoorn (1997) suggested that secure attachment may promote the development of attentional control, since the sensitive parent aims at creating dyadic synchronicity. A secure infant-parent attachment relationship has been associated with interactive competence (Thompson 1999), whereas insecure and disorganized attachments have been associated with poor interactive competence (Moss et al. 1999; Solomon and George 1999). Face-to-face attention and social referencing in young children take place mainly during interaction with the attachment figure. Campos (1983), Emde (1992) and Feinman and Lewis (1983) have hypothesized that social referencing is based on affective communication rather than on instrumental communication, and this is exactly what Ainsworth (1992) emphasized from an attachment perspective. Indeed, Scholmerich et al. (1997) showed that insecurely attached children, in particular children with disorganized attachments, showed less face-to-face attention and less coordinated joint attention to objects compared to securely attached children.

In sum, the level of reciprocal interactions appears to vary between typical developing children with a secure and disorganized attachment. Typically developing children with a secure attachment interact in an open and reciprocal way whereas children with insecure-disorganized attachment at times lack synchronicity in their interchanges with the attachment figure (Hesse and Main 2006). The emergence and further development of joint attention skills may depend on the reciprocity with which both child and parent initiate interaction and respond to each other (Raver and Leadbeater 1995).

\section{Joint Attention, Attachment and Autism}

Children with autism show deficiencies in joint attention behaviors (Curcio 1978; Loveland and Landry 1986; Mundy et al. 1986; Wetherby and Prutting 1984). In research on autism, 'joint attention' however tends to refer to just a few of the joint attention skills such as 'gaze following,' 'pointing' behavior' and 'mutual gazing' or 'joint visual attention' (Carpenter et al. 2002). Children with autism are specifically impaired in those behaviors that involve another person, e.g., pointing, showing, or making eye contact (Lewy and Dawson 1992; McEvoy et al. 1993; Mundy et al. 1986). Phillips et al. (1995) found that children with autism did not make eye contact with an adult following an ambiguous event. In a retrospective study, Adrien et al. (1993) reported an overall lack of eye contact in infants between $0-2$ years of age. Observing first birthday parties of children later diagnosed with ASD, Osterling and Dawson (1994) found that they showed 
reduced 'looking at other people' and less 'showing objects' or 'pointing' behavior. In the retrospective studies of Dawson et al. (1998), Baranek (1999), and Werner et al. (2000), children with autism did not respond adequately to name calling in the first years of life.

Difficulties in joint attention may be related to abnormal social gaze behavior in children with autism. These deviances vary from abnormal low frequency of gaze behavior (Hutt and Ounsted 1966; Kasari et al. 1993; Pedersen et al. 1989), and different 'patterns' of gaze (Carpenter et al. 2002) to abnormal timing rather than low amount of gaze (Buitelaar et al. 1991; Van Engeland et al. 1985; Willemsen-Swinkels et al. 1998). The deviant timing of social gaze behavior may lead to asynchronies in the interaction between child and parent, and thus to impaired joint attention behaviors (Morales et al. 2000).

The social interaction and orientation problems of infants with autism may decrease the amount of attention to their mothers (Sigman et al. 2004). Children with autism with a secure attachment relationship may however show more reciprocal interaction with their caregiver compared to their counterparts with a disorganized attachment relationship. Parental sensitivity may affect the development of joint attention in typically developing children, and perhaps also in atypically developing children like children with ASD. When caregivers are able to adapt their interactive reciprocal behavior to their children's abilities, this may result higher levels of joint attention in children with ASD.

\section{This Study}

In this study we distinguished two types of joint attention behaviors. 'Basic joint attention' behaviors are joint attention behaviors that develop during the first year of life and are suggested to be related to language development. 'Associated joint attention' behaviors are joint attention behaviors that are not directly related to language development, and include checking and follow pointing (Charman 2003; Mundy et al. 1990).

Although most joint attention skills develop under the age of three, the majority of studies on joint attention in children with autism involved children older than 3 years of age, due to difficulties in diagnosing autism under this age. We investigated joint attention behaviors of 78 young children (mean age 25.7 (SD 6.1) months) with and without ASD to examine whether children at this age also show deficits in joint attention, as has been found in children with ASD at a later age. Because joint attention is associated with cognitive functioning, control groups in previous studies were matched for developmental level, resulting in large differences in chronological age. To investigate the contribution of developmental level to the development of joint attention, control groups should be matched on chronological age and developmental level. Therefore we included two control groups (differing in developmental level) who were matched on chronological age with the ASD group. Our study is unique in studying the development of joint attention in very young children with autism compared with age matched controls.

We predicted that young children without clinical disorders would show more joint attention skills than their age mates with a clinical disorder. We also expected young children without ASD to show more joint attention than children with ASD, as has been found in studies with older children with ASD and in retrospective studies.

Since attention may be influenced by parenting processes, and because secure attachment may promote the development of attentional control, we expected that children with developmental delays but with secure attachment relationships might show more advanced joint attention abilities than children with developmental delays with insecure attachment relationships. Children with a disorganized attachment relationship and a developmental delay may show least joint attention behaviors.

To test these hypotheses, we investigated joint attention behaviors of children with and without developmental disorders, including $\mathrm{AD}$ and PDDNOS, and in children with and without secure and disorganized attachment classifications.

\section{Materials and Methods}

\section{Participants}

All children were recruited from a population based sample of about 30,000 children at the age of 14 months, participating in a large screening study in a geographical defined area, the province of Utrecht (The Netherlands) for early detection for social developmental delays, using the Early Screening of Autistic Traits questionnaire (ESAT). Details about the screening are described by Swinkels et al. (2006) and Dietz et al. (2006). Children who were found to be screen-positive for social developmental delay were invited for further investigations at the Department of Child and Adolescent Psychiatry in Utrecht. The study design and screening procedure were approved by the Medical Ethics Review Board of the University Medical Centre Utrecht.

\section{Diagnostic Assessments}

Psychiatric examinations included a series of six visits that were scheduled within a period of 5 weeks at 24 months of age. At each weekly visit, the social and communicative behavior of the child was observed in a small group of 
young children and their parents. The assessments included a standardized parental interview, developmental history, and the Vineland Social-Emotional Early Childhood Scales (Sparrow et al. 1997); standardized behavior observation (Autism Diagnostic Observation Schedule ADOS-G, (DiLavore et al. 2000), and pediatric examination and medical work-up. During one of the six visits the SSP (Ainsworth et al. 1978) was conducted, and as part of one of the other visits joint attention behavior was measured. At the proper age of 42 months the child was re-examined, and apart from the earlier described measurement, the Autistic Diagnostic Interview-Revised (ADI-R; Lord et al. 1994) and a second parental interview were used. On the basis of all available information, and on the basis of clinical judgment, a diagnosis was given by an experienced child psychiatrist. The inter-rater reliability for the clinical diagnoses among three child psychiatrists (ED, JB, HvE) was calculated first for two diagnostic categories; ASD or other than ASD, with 92\% agreement (kappa 0.74, $n=38$ ). Second, the inter-rater reliability for all diagnostic categories was $79 \%$ (kappa $0.67, n=38$ ). Diagnostic discrepancies were discussed to consensus. More details on the psychiatric diagnoses will be reported elsewhere (Van Daalen et al., Early detection of autism spectrum disorders: Reliability and stability of diagnosis, in preparation). These reliability rates are comparable to those reported in the studies of Stone et al. (2002) and Fombonne et al. (2004), also concerning autism in very young children.

\section{Diagnostic Groups}

Children who were classified with AD, PDDNOS, MR, or Language Delay at the proper age of 42 months were included in the analyses on joint attention behavior under the age of 30 months. As a result, data of 38 children with a developmental disorder or delay were available. The children were divided across the four groups as follows; AD $(n=11)$, PDDNOS $(n=9), \operatorname{MR}(n=8)$, and language delay $(n=10)$, with an overall mean age of 28.00 months $(\mathrm{SD}=5.70)$. The mean developmental level as measured by the Mullen Scales of early learning (Mullen 1995) of the children with $\mathrm{AD}$ was $51.18(\mathrm{SD}=4.26)$ and the mean developmental level of the group of children with PDDNOS $73.44(\mathrm{SD}=16.99)$. Children with $\mathrm{MR}$ had an overall mean developmental level of $54.00(\mathrm{SD}=3.78)$. The mean developmental level of the group with language delay was $81.00(\mathrm{SD}=9.09)$. The diagnosis Language Delay was based on the difference of 1 SD between expressive and receptive language of these children.

For some analyses, a further contrast was formed of children with Autism Spectrum Disorders (ASD; $n=20$; mean age 29.45, $\mathrm{SD}=5.70$ ) which included children with $\mathrm{AD}$ and children with PDDNOS, versus children without Autism Spectrum Disorder (non-ASD; $n=18$; mean age 26.39, $\mathrm{SD}=5.41$ ) which included children with $\mathrm{MR}$ and children with language delay. The mean developmental level of the children with ASD was $61.20(\mathrm{SD}=16.13)$ and the mean developmental level of the group of children without ASD $69.00 \quad(\mathrm{SD}=15.50)$. No differences were detected in age and developmental level among the different clinical groups.

We also included two control groups. One control group contained children who were referred to the hospital due to doubt about their development. Clinical investigation however showed that these children were free from clinical diagnoses. This group (atypical controls, AC, $n=25$ ) had an overall mean age of 20.72 months $(\mathrm{SD}=5.27)$ and a mean developmental level of $84.72(\mathrm{SD}=14.75)$. The other control group (normal controls, NC, $n=15$ ) had an overall mean age of 28.20 months $(\mathrm{SD}=1.82)$ and a mean developmental level of $101.93(\mathrm{SD}=13.57)$. This group of children was screen negative on the ESAT. Based on parental reports and observations of the psychologists, these children were free from any child psychiatric disorder. To obtain this NC group, parents were contacted through wellbaby clinics (see Dietz et al. 2006). Parents who agreed to participate were interviewed about the child's social and cognitive development at home. Descriptive characteristics of the children are presented in Table 1.

\section{Procedure}

In the series of six visits that were scheduled between 20 and 30 months of age, one session was devoted to the assessment

Table 1 Characteristics of the clinical and control children $(N=78)$

\begin{tabular}{|c|c|c|c|c|c|c|c|c|}
\hline & $\mathrm{AD}$ & PDDNOS & MR & LD & $\mathrm{AC}$ & $\mathrm{NC}$ & ASD & Non-ASD \\
\hline$N$ & 11 & 9 & 8 & 10 & 25 & 15 & 20 & 18 \\
\hline Gender $\mathrm{M} / \mathrm{F}$ & $7 / 4$ & $6 / 3$ & $6 / 2$ & $9 / 1$ & $18 / 7$ & $7 / 8$ & $13 / 7$ & $15 / 3$ \\
\hline Age & $30.6(4.9)$ & $28.1(6.7)$ & $27.0(4.9)$ & $25.9(6.0)$ & $20.7(5.3)$ & $28.2(1.8)$ & $29.5(5.7)$ & $26.4(5.4)$ \\
\hline Developmental level & $51.2(4.3)$ & $73.4(17.0)$ & $54.0(3.8)$ & $81.0(9.1)$ & $84.7(14.8)$ & $101.9(13.6)$ & $61.2(16.1)$ & $69.0(15.5)$ \\
\hline Autistic Symptoms & $35.9(6.2)$ & $17.7(12.6)$ & $19.1(10.5)$ & $10.6(5.8)$ & $11.2(7.7)$ & & $27.7(13.2)$ & $14.4(9.1)$ \\
\hline Security of attachment & $-1.8(3.1)$ & $2.0(2.8)$ & $-1.4(4.1)$ & $1.5(2.9)$ & $1.8(2.2)$ & $2.0(2.0)$ & $-0.1(3.5)$ & $.1(3.7)$ \\
\hline Disorganization & $5.0(3.0)$ & $2.8(2.8)$ & $3.78(3.0)$ & $3.0(2.9)$ & $3.2(2.9)$ & $1.7(1.2)$ & $4.0(3.1)$ & $3.3(2.9)$ \\
\hline
\end{tabular}


of joint attention. Other sessions were used for the psychiatric assessment, which included the ADOS, and one assessment consisted of the SSP to observe the attachment relationship of the child with the mother (see also Naber et al. 2007). All assessments took place at the University Medical Center of Utrecht, at the Department of Child and Adolescent Psychiatry, with the mother of the child.

\section{Measures}

Strange Situation Procedure Ainsworth et al. (1978) developed the SSP to observe the attachment behavior of the child towards the mother. The SSP contains two separations and two reunions with the mother. Securely attached children show a balance in their proximity seeking and exploration of the environment while avoidant children minimize their expression of negative emotions and attachment behavior, and ambivalent children maximize this expression. These three 'organized' strategies (Ainsworth et al. 1978) may be considered as adaptive to the infants' environment, and each is supposed to allow for a maximum of proximity to the specific attachment figure (Main and Solomon 1990). Children who show disorganized attachment are characterized by a (momentary) breakdown of any organized strategy of emotion regulation during the SSP (Main and Solomon 1990; Van IJzendoorn et al. 1999). The SSP was coded by two trained observers (SWS \& MBK), who were unaware of the children's diagnoses. Agreement for the four attachment classifications $(n=28)$ corrected for chance was 0.74 (Cohen's Kappa). We also used the simplified Richter et al. (1988) algorithm to compute continuous scores for attachment security (Van IJzendoorn and Kroonenberg 1990) on the basis of the interactive SSP scale scores for proximity seeking, contact maintaining, resistance and avoidance for these children. Disorganized attachment was coded using the Main and Solomon (1990) 9-point coding system for disorganized/ disoriented attachment. Inter-coder reliability was 0.77 (Pearson's correlation coefficient) for Richter's security score, and 0.66 for the continuous rating of disorganized attachment.

Numerous studies on attachment in autism (reviewed in Rutgers et al. 2004) have shown that attachment security is compatible with autism, and can be assessed with Strange Situation type of procedures. Children with ASD are capable of forming a secure attachment relationship with their parents already at a young age, although they appear to be somewhat less securely attached to their parents compared to non-clinical children (Rutgers et al. 2004; Naber et al. 2007). However, coding attachment security or disorganization in children with autistic disorders, observers should take the individual's own baseline behavior into account as displayed in the first few Strange Situation episodes, in order to differentiate between (disorganization of) attachment behaviors and behaviors that are typical for children with autism (see Willemsen-Swinkels et al. 2000, and Naber et al. 2007). In both studies the validity of classifying children with autism as disorganized in the sense of attachment theory was documented through recordings of heart rate during the Strange Situation procedure.

Joint Attention The assessment for joint attention was performed according to protocol. The tasks were performed by the child under supervision of the experimenter and under supervision of the parent. During performance of the tasks with the experimenter, the parent was also in the room, but was instructed to stay passive, although the parent was allowed to respond to the child. During tasks with the parent, the experimenter was not in the room.

Joint Attention Tasks with the Experimenter A series of tasks was conducted within a time span of $25 \mathrm{~min}$. The tasks were based on earlier developed tasks to provoke checking, gazing, pointing and other joint attention behavior of the child. The tasks are described in Table 2.

Joint Attention Tasks with the Mother After the joint attention tasks with the experimenter, the child and mother were left together in the room. The mother was instructed to change toys every 3 min after a knock on the one way screen. The tasks the child performed with their mother are also presented in Table 2. Joint attention behaviors were coded from videotape by means of "The Observer" (Noldus 1991), a software system for recoding, coding and analyzing sequences, frequencies and durations of observed events. The behaviors that were coded were 'attention object,' 'checking,' 'pointing,' 'give' an object, 'following one's pointing' and 'gaze following' (see Table 3). All behaviors were coded for frequency per minute except for 'attention object,' which was coded for duration of time (\%). Intercoder agreement of two independent coders (KM $\& \mathrm{PH}$ ) was 0.73 (Cohen's Kappa, $n=15$ ).

Severity of Autistic Symptoms To quantify the severity of autistic symptoms according to Lord et al. (2001), the raw data of the ADOS administered at the age of 2 years was used. The ADOS offers the opportunity to quantify deficits across the autism spectrum in individuals with significant impairments, controlling for effects of language and cognitive delay (see Lord et al. 2001). It has been suggested that quantitative measures of social reciprocity and repetitive behaviors and interests, with separate quantification of expressive language level and nonverbal intelligence, most accurately reflect the range of behavioral phenotypes in autism spectrum disorders (Lord et al. 2001). The total sum 
Table 2 Description of tasks with experimenter and mother

\begin{tabular}{|c|c|}
\hline Task & Description \\
\hline \multicolumn{2}{|c|}{ Tasks with the experimenter } \\
\hline Attention task & $\begin{array}{l}\text { Child and experimenter read a book together while the experimenter asks the child to point to different } \\
\text { subjects in the book and points towards objects herself. During this reading the experimenter activates } \\
\text { a music box that might distract the attention of the child. }\end{array}$ \\
\hline Building a tower & $\begin{array}{l}\text { During this task, the child has to build a tower of bricks. The child has to ask the experimenter for more } \\
\text { bricks. Based on the ADOS. }\end{array}$ \\
\hline Imitation task & $\begin{array}{l}\text { The experimenter activates the beanbag that produces a sound by touching her forehead with the beanbag. } \\
\text { The child has to imitate this behavior. Based on the light-box task (Meltzoff 1988). }\end{array}$ \\
\hline Gaze following task & According to the description of Phillips et al. (1995). \\
\hline Imitation task 2 & $\begin{array}{l}\text { Task based on the task developed by Tiegerman and Primavera (1984), using the following five objects; } \\
\text { spoon, car, tiny doll, hairbrush, castagnettes, where the child is invited to imitate the experimenter. }\end{array}$ \\
\hline Imitation/cognition task & The child has to activate a toy after the demonstration of the experimenter. \\
\hline \multicolumn{2}{|l|}{ Tasks with mother } \\
\hline Doll, bed and bottle & The mother was instructed to stimulate the child to nurse the doll like a baby. \\
\hline Hammer and box & $\begin{array}{l}\text { This task was based on requesting behavior of the child towards the mother. The mother was instructed to } \\
\text { demonstrate the hammering. The child had to request for the hammer. The mother also instructed which } \\
\text { brick to hammer on. }\end{array}$ \\
\hline Peek-a-boo & $\begin{array}{l}\text { The mother was instructed to play peek-a-boo with the child, using a towel, which could be switched } \\
\text { between mother and child. }\end{array}$ \\
\hline Picture drawing & The mother was instructed to draw a picture together with the child with chalk on a blackboard. \\
\hline Sing a song & The mother was instructed to sing a song together with the child that involved gestures. \\
\hline
\end{tabular}

score of the ADOS reflects this range of behavioral phenotypes and is therefore used as a continuous score for intensity of autism (number of autistic symptoms). Following the ADOS algorithm, value 3 was recoded into value 2 before analyzing. ADOS scores of all clinical groups are presented in Table 1. The inter-rater reliability for the ADOS sum score among a child psychiatrist and two psychologists was 97\% (kappa 0.62, $n=6$; Cohen's Kappa). Some of the ADOS items concern joint attention abilities of the child. Since this may confound the analyses regarding joint attention and number of autistic characteristics (ADOS-score), the ADOS scores were recalculated excluding the joint attention items. Using the total ADOS scores or the modified ADOS scores (excluding joint attention items) did not yield different results. Therefore, results using the overall ADOS scores are reported below.

\section{Data Analyses}

Missing Data Due to factors like tiredness of the child, there was some missing data scattered across variables and subjects. By estimating the maximum likelihood function at the individual level (Arbuckle and Wothke 1999; Shafer and Graham 2002; Wothke 2000), data of all children $(N=78)$ were included in the analyses.

Factor Analyses We distinguished two types of joint attention behaviors, BJA and AJA (see Introduction). Principal Component Analysis supported this distinction. A two factor solution was found. Using varimax rotation and a cut-off of 0.55 for inclusion of a variable in one of the factors (Tabachnick and Fidell 2001), only one of six variables did not load on any factor. The first factor (eigen

Table 3 Brief description of joint attention and related behaviors

\begin{tabular}{|c|c|c|c|}
\hline Joint Attention Behavior & Assessment & Definition & Mean Value $(M)(\mathrm{SD})$ \\
\hline Attention object & Duration & The child and adult are looking at the same object of request. & $102.36(22.73)$ \\
\hline Gaze following & freq./min & $\begin{array}{l}\text { The child is looking in the direction where the adult is looking at, other that the } \\
\text { object of attention during the task. }\end{array}$ & $0.07(.09)$ \\
\hline Pointing & freq./min & The child is pointing at an object with his/her index finger & $0.47(.42)$ \\
\hline Checking & freq. $/ \mathrm{min}$ & $\begin{array}{l}\text { The child is looking briefly in the eye-direction of the adult (less than } 3 \text { seconds) } \\
\text { to verify its behavior. }\end{array}$ & $1.52(1.29)$ \\
\hline Follow pointing & freq./min & The child is looking where the adult is pointing at & $0.04(.08)$ \\
\hline Giving & freq./min & The child is offering an object to the adult & $0.39(.23)$ \\
\hline
\end{tabular}


Table 4 Correlations between joint attention variables and factors with loading of observed joint attention behaviors $(N=78)$

\begin{tabular}{llllllll}
\hline & Attention object & Gaze follow & Point & Check & Follow pointing & Give & Factor $1^{\mathrm{a}}$ \\
\hline Attention object & - & & & & \\
Gaze follow & $0.24^{*}$ & - & & & 0.77 \\
Point & $0.34^{* *}$ & 0.16 & - & & 0.62 \\
Check & $0.38^{* *}$ & -0.11 & 0.16 & - & & 0.66 \\
Follow pointing & 0.14 & -0.01 & 0.21 & $0.29^{*}$ & - & 0.75 \\
Give & $0.28^{*}$ & $<0.01$ & 0.18 & 0.13 & 0.03 & - & 0.61 \\
\hline
\end{tabular}

${ }^{*}$ Correlation is significant at the 0.05 level

** Correlation is significant at the 0.01 level.

${ }^{\text {a }}$ Eigenvalue $=1.92$, explains $31.98 \%$ of the variance

${ }^{\mathrm{b}}$ Eigenvalue $=1.18$, explains $19.58 \%$ of the variance

value 1.92) consisted of the three behaviors Attention object, 0.77 Pointing, 0.66, and Gaze following, 0.62, and is labeled as BJA. Factor 2 (eigen value 1.18) consisted of the two behaviors Check, 0.75 and Follow pointing, 0.75, corresponding to AJA. The correlation matrix for the behaviors and the factor loadings are presented in Table 4 . The two factors are in concordance with the distinction in joint attention behaviors as described in the literature. The standardized scores on these two factors were used in the following analyses.

Joint Attention Associations of joint attention with diagnosis, attachment security, and attachment disorganization were examined. The first analysis included all clinical and control children. Following this analysis, contrast analyses regarding clinical versus control groups and ASD versus non-ASD were performed. When significant differences were found, contrasts of $\mathrm{AD}$ versus MR were explored.

Hierarchical Multivariate Regression Analyses The contribution of age, developmental level (Mullen Scale of Early Learning; Mullen 1995), intensity of the autistic disorder (ADOS), and attachment (security and disorganization) to the variance in joint attention behaviors was tested with a hierarchical multiple regression analysis.

\section{Results}

Joint Attention Behavior and Diagnosis An overall analysis including all clinical and control groups was conducted for both BJA and AJA. A significant difference between the groups was detected for both BJA $(F(5,77)=13.61, p<$ $0.01)$ and $\operatorname{AJA}(F(5,77)=4.74, p<0.01)$. Contrast analysis of clinical versus control group showed that children in the control group displayed more $\mathrm{BJA}(M=0.48, \mathrm{SD}=0.73)$ than children in the clinical group $(M=-0.51, \mathrm{SD}=1.00), t(76)=$ $-4.96, p<0.01, d=1.12$. Children in the control group also displayed more AJA $(M=0.38, \mathrm{SD}=1.07)$ than children in the clinical group $(M=-0.40, \mathrm{SD}=0.74), t(76)=-3.74, p<$ $0.01, d=0.85$. Contrast analyses of BJA revealed that children with ASD $(M=-0.88, \mathrm{SD}=0.84)$ showed less BJA compared to children without ASD $(M=-0.09, \mathrm{SD}=$ 1.01), $t(36)=-2.57, p=0.02, d=0.83$. Children with ASD also showed less AJA $(M=-0.77, \mathrm{SD}=0.44)$ than children without ASD $(M<0.01, \mathrm{SD}=0.81), t(36)=-3.72, p<0.01$, $d=1.21$. Children with AD showed less AJA $(M=-0.88$, $\mathrm{SD}=0.39)$ than children with $\mathrm{MR}(M=-0.06, \quad \mathrm{SD}=0.72)$, $t(17)=-2.90, p=0.02, d=1.33$. There was no significant difference on BJA between children with $\mathrm{AD}$ and children with MR without AD. Mean values of both BJA and AJA are presented in Table 5.

Table 5 Mean $z$-values and mean values of basic joint attention and associated joint attention

\begin{tabular}{llllll}
\hline & $n$ & BJA Mean $(z)$ SD & AJA Mean $(z)$ SD & BJA Mean SD & AJA Mean SD \\
\hline AD & 11 & $-1.23(0.61)$ & $-0.88(0.39)$ & $24.92(4.63)$ & $0.22(0.17)$ \\
PDDNOS & 9 & $-0.45(0.92)$ & $-0.63(0.49)$ & $30.86(7.04)$ & $0.37(0.19)$ \\
MR & 8 & $-0.74(1.03)$ & $-0.06(0.72)$ & $28.68(7.89)$ & $0.60(0.36)$ \\
language delay & 10 & $0.42(0.68)$ & $0.06(0.90)$ & $37.52(5.22)$ & $0.68(0.42)$ \\
AC & 25 & $0.25(0.64)$ & $0.26(1.10)$ & $40.93(5.64)$ & $0.79(0.49)$ \\
NC & 15 & $0.87(0.74)$ & $0.59(1.02)$ & $33.59(6.43)$ & $0.92(0.45)$ \\
ASD & 20 & $-0.88(0.84)$ & $-0.77(0.44)$ & $30.43(7.63)$ & $0.29(0.19)$ \\
Non-ASD & 18 & $-0.09(1.01)$ & $<0.01(0.81)$ & $37.98(5.60)$ & $0.46(0.38)$ \\
Clinical groups & 38 & $-0.51(1.00)$ & $-0.40(0.74)$ & $0.38(1.07)$ & $0.84(0.47)$ \\
Control groups & 40 & $0.48(0.73)$ & &
\end{tabular}


Security of Attachment Analyses started with a contrast analysis including all clinical and control groups for both BJA and AJA for children with and without secure attachment. Contrast analysis with all children included showed that children with a secure attachment $(n=48)$ showed more BJA $(M=0.28, \mathrm{SD}=0.89)$ compared to children without a secure attachment classification $(n=30$, $M=-0.45, \quad \mathrm{SD}=1.02), t \quad(76)=-3.26, p<0.01, d=0.76$. Children with secure attachment also displayed more AJA $(M=0.22, \mathrm{SD}=1.05)$ than children without secure attachment $(M=-0.35, \mathrm{SD}=0.81), t(76)=-2.70, p<0.01, d=$ 0.63 . Contrast analyses within the clinical groups, however, did not reveal any significant difference. Mean values of both BJA and AJA are displayed in Table 6.

Disorganization of Attachment We started with a contrast analysis including all clinical and control groups for BJA and AJA for children with $(n=18)$ and without $(n=60)$ disorganized attachment. Children without disorganized attachment showed overall more BJA $(M=0.24, \mathrm{SD}=0.86)$ than children with disorganized attachment $(M=-0.79, \mathrm{SD}=$ 1.03), $t(76)=3.85, p<0.01, d=1.03$. Children without disorganized attachment also performed more AJA $(M=$ $0.17, \mathrm{SD}=1.04)$ than children with disorganized attachment $(M=-0.56, \mathrm{SD}=0.60), t \quad(76)=2.81, p<0.01, d=0.76$. Analyses within the clinical group also showed that clinical children without disorganized attachment $(n=26)$ showed more $\mathrm{BJA}(M=-0.27, \mathrm{SD}=0.84)$ than clinical children with disorganized attachment $(n=12)(M=-1.08, \mathrm{SD}=1.13)$, $t(36)=2.20, p=0.04, d=0.77$, but there were no significant differences between these two groups for AJA. In the group of children with ASD, children without disorganized attachment $(n=12)$ showed more BJA $(M=-0.49, \mathrm{SD}=$
0.91) than children with disorganized attachment $(n=8)$ $(M=-1.48, \mathrm{SD}=1.05), t(18)=2.24, p=0.04), d=1.02$. No significant differences were detected for AJA. Mean values of both BJA and AJA are displayed in Table 6 .

Multivariate Analyses Hierarchical regression analysis was used to test whether age, developmental level, number of autistic characteristics, attachment security and disorganization (Table 7) contributed to the prediction of BJA and AJA. Table 7 displays the correlation between the variables, the standardized regression coefficients $(\beta), R$, and $R^{2}$ after entry of the variables age, developmental level, number of autistic characteristics and attachment. In the first step, age was entered. In step 2, developmental level contributed significantly to the equation, $F(2,59)=8.99, p<0.01$, with $21 \%$ of the variance explained. In step 3 , number of autistic characteristics contributed significantly to the equation, $F(3,58)=9.33, p<0.01$, with $29 \%$ of the variance explained. Although the equation in step 4 was significant, $F(5,55)=$ 5.83, $p<0.01$, security of attachment and attachment disorganization did not significantly improve $R^{2}$. Higher developmental level and a lower number of autistic symptoms predicted more BJA.

Table 7 also displays the results of the analysis predicting AJA. In the first step, age was entered, contributing significantly to the equation, $F(1,60)=4.71$, $p=0.03$, with $5 \%$ of the variance explained. In step 2 , developmental level contributed significantly to the equation, $F(2,59)=7.25, p<0.01$, with $17 \%$ of the variance explained. In step 3 , number of autistic characteristics contributed significantly to the equation, $F(3,58)=8.01, p<$ 0.01 , with $26 \%$ of the variance explained. Although the equation in step 4 was significant, $F(5,55)=4.81, p<0.01$,

Table 6 Mean $z$-values of securely (B) and insecurely (nB) attached children and children with (D) and without (nD) disorganized attachment on basic joint attention and associated joint attention behavior towards the experimenter $(N=78)$

\begin{tabular}{llllll}
\hline & $n$ & BJA Mean(z) SD & AJA Mean(z) SD & BJA Mean SD & AJA Mean SD \\
\hline ASD-secure & 9 & $-0.56(1.03)$ & $-0.73(0.70)$ & $30.13(7.74)$ & $.031(0.24)$ \\
ASD-not secure & 11 & $-1.15(1.06)$ & $-0.80(0.57)$ & $25.52(4.48)$ & $0.27(0.15)$ \\
nASD-secure & 10 & $0.02(0.68)$ & $0.11(1.01)$ & $34.97(5.95)$ & $0.72(0.45)$ \\
nASD-not secure & 8 & $-0.31(0.88)$ & $-0.21(0.54)$ & $31.86(9.76)$ & $0.56(0.29)$ \\
Clinical-secure & 19 & $-0.26(0.89)$ & $-0.29(0.95)$ & $32.68(7.10)$ & $0.53(0.41)$ \\
Clinical-not secure & 19 & $-0.79(1.05)$ & $-0.55(0.62)$ & $38.19(7.65)$ & $0.39(0.26)$ \\
Control-secure & 29 & $0.64(0.69)$ & $0.56(0.96)$ & $36.15(5.77)$ & $0.87(0.44)$ \\
Control-not secure & 11 & $0.13(0.63)$ & $-0.02(1.07)$ & $24.26(4.68)$ & $0.74(0.56)$ \\
ASD-disorganized & 8 & $-1.48(1.05)$ & $-0.77(0.67)$ & $34.82(6.63)$ & $0.27(0.18)$ \\
ASD-not disorganized & 12 & $-0.49(0.91)$ & $-0.77(0.60)$ & $33.32(8.31)$ & $0.31(0.21)$ \\
nASD-disorganized & 4 & $-0.28(0.91)$ & $0.08(0.88)$ & $27.69(7.15)$ & $0.50(0.11)$ \\
nASD-not disorganized & 14 & $-0.08(0.76)$ & $-0.66(0.62)$ & $31.70(7.64)$ & $0.34(0.19)$ \\
Clinical-disorganized & 12 & $-1.08(1.13)$ & $-0.31(0.87)$ & $33.54(4.86)$ & $0.51(0.39)$ \\
Clinical-not disorganized & 26 & $-0.27(0.84)$ & $-0.28(0.52)$ & $38.76(5.42)$ & $0.57(0.19)$ \\
Control-disorganized & 6 & $-0.23(0.50)$ & $0.52(1.03)$ & & $0.88(0.50)$ \\
Control-not disorganized & 34 & $0.63(0.66)$ & & & \\
\hline
\end{tabular}


Table 7 Multiple hierarchical regression analysis predicting BJA and AJA from age, developmental level, autistic symptoms, and security and disorganization of attachment

\begin{tabular}{|c|c|c|c|c|c|c|c|c|c|c|c|c|c|c|c|}
\hline & Age & $\begin{array}{l}\text { Dev. } \\
\text { Level }\end{array}$ & $\begin{array}{l}\text { Aut. } \\
\text { Symp }\end{array}$ & $\begin{array}{l}\text { Sec. } \\
\text { Att. }\end{array}$ & $\begin{array}{l}\text { D. } \\
\text { Att. }\end{array}$ & $\begin{array}{l}\text { B } \\
\text { BJA }\end{array}$ & $\begin{array}{l}\text { SE B } \\
\text { BJA }\end{array}$ & $\beta$ BJA & $\begin{array}{l}R \\
\text { BJA }\end{array}$ & $\begin{array}{l}R^{2} \\
\text { BJA }\end{array}$ & $\begin{array}{l}\text { B } \\
\text { AJA }\end{array}$ & $\begin{array}{l}\text { SE B } \\
\text { AJA }\end{array}$ & $\beta$ AJA & $\begin{array}{l}R \\
\mathrm{AJA}\end{array}$ & $\begin{array}{l}R^{2} \\
\text { AJA }\end{array}$ \\
\hline Step 1 & & & & & & & & & 0.13 & 0.02 & & & & 0.30 & $0.09^{*}$ \\
\hline Age & & & & & & -0.02 & 0.02 & -0.13 & & & -0.03 & 0.01 & $-0.30^{*}$ & & \\
\hline Step 2 & & & & & & & & & 0.48 & $0.23^{* *}$ & & & & 0.48 & $0.23^{* *}$ \\
\hline Age & & & & & & 0.02 & 0.02 & 0.15 & & & $<-0.01$ & 0.01 & -0.07 & & \\
\hline $\begin{array}{l}\text { Developmental } \\
\text { level }\end{array}$ & & & & & & 0.03 & $<0.01$ & $0.54^{* *}$ & & & 0.02 & $<0.01$ & $0.44^{* *}$ & & \\
\hline Step 3 & & & & & & & & & 0.58 & $0.33^{* *}$ & & & & 0.55 & $0.30^{*}$ \\
\hline Age & & & & & & 0.02 & 0.02 & 0.16 & & & $<-0.01$ & 0.01 & -0.06 & & \\
\hline $\begin{array}{l}\text { Developmental } \\
\text { level }\end{array}$ & & & & & & 0.02 & $<0.01$ & 0.29 & & & 0.01 & $<0.01$ & 0.22 & & \\
\hline Autistic symptoms & & & & & & -0.03 & 0.01 & $-0.41^{* *}$ & & & -0.02 & $<0.01$ & $-0.35^{*}$ & & \\
\hline Step 4 & & & & & & & & & 0.59 & 0.35 & & & & 0.55 & 0.30 \\
\hline Age & 1.00 & & & & & 0.03 & 0.02 & 0.17 & & & $<-0.01$ & 0.01 & -0.05 & & \\
\hline $\begin{array}{l}\text { Developmental } \\
\text { level }\end{array}$ & $-0.53^{* *}$ & 1.00 & & & & 0.01 & $<0.01$ & 0.27 & & & $<0.01$ & $<0.01$ & 0.22 & & \\
\hline $\begin{array}{l}\text { Autistic } \\
\text { symptoms }\end{array}$ & $0.34^{* *}$ & $-0.62^{* *}$ & 1.00 & & & -0.03 & 0.01 & $-0.37^{*}$ & & & -0.02 & $<0.01$ & $-0.34^{*}$ & & \\
\hline $\begin{array}{l}\text { Security of } \\
\text { attachment }\end{array}$ & -0.21 & $0.33^{* *}$ & $-0.38^{* *}$ & 1.00 & & 0.04 & 0.04 & 0.12 & & & 0.01 & 0.03 & 0.07 & & \\
\hline $\begin{array}{c}\text { Disorganization } \\
\text { of attachment }\end{array}$ & 0.05 & -0.22 & $0.31^{* *}$ & $-0.35^{* *}$ & 1.00 & $<-0.01$ & 0.04 & -0.03 & & & 0.01 & 0.03 & 0.06 & & \\
\hline
\end{tabular}

${ }^{*}$ Correlation is significant at the 0.05 level

${ }^{* *}$ Correlation is significant at the 0.01 level

security of attachment and attachment disorganization did not significantly improve $R^{2}$. Higher developmental level and a lower number of autistic symptoms predicted more AJA.

\section{Discussion}

We investigated early joint attention behaviors in children later diagnosed with autism spectrum disorders, other developmental delays and typically developing children. Based on the literature and empirically supported by factor analysis, we distinguished Basic Joint Attention (BJA) and Associated Joint Attention (AJA). As expected, clinical children showed less BJA and AJA compared to control children, and children with ASD showed less BJA and AJA compared to children without ASD. Securely attached children showed more BJA and AJA than non-securely attached children, and children with disorganized attachment showed less BJA and AJA compared to children without disorganized attachment. Within the clinical group and within the group of children with ASD again children with disorganized attachment showed less BJA than children without disorganized attachment, but no differences for AJA were found within the ASD group.
Controlling for age and developmental level, the number of autistic characteristics was predictive of joint attention performance. Children with more autistic characteristics showed less joint attention behavior. Security and disorganization of attachment did not contribute to the prediction of joint attention behaviors beyond the influence of autistic characteristics.

\section{BJA and AJA}

Factor analysis supported empirically the distinction between BJA and AJA that prevails in the literature. Differences between these clusters of behaviors may be due to the underlying structures of the behaviors. Alternating of attention between an object and a person is not always called 'joint attention.' According to Tomasello (1995) it is only joint attention when the child is concerned with the adult's attention to the object. The behaviors described in BJA may refer to behaviors that imply joint attention, but it is not necessary for the child to understand the other's intention. Checking behavior and follow pointing behavior on the other hand cannot be performed properly when the other's intention is not understood. Therefore, whereas 'pointing' and 'gaze following' might belong to the behavioral repertoire of the child without the full awareness of others' minds, 'checking' and 'follow pointing' are 
indicators of this awareness and express the 'shared attention mechanism' more explicitly (Leekam et al. 2000).

\section{BJA and AJA in Clinical and Control Groups}

Children without a clinical diagnosis demonstrated more BJA and AJA than the clinical groups. This finding was expected because joint attention development is, among others, related to the developmental level of the child. Children from the control group all showed 'normal' intelligence, whereas a high percentage of the children from the clinical groups were functioning below normal developmental level. The differences between the clinical and control group, therefore, might be caused by differences in cognitive functioning and the related absence or presence of a developmental delay. However, after controlling for developmental level, we still found that children with more autistic symptoms displayed less BJA and AJA.

When comparing children with $\mathrm{AD}$ and MR (without $\mathrm{AD}$ ), the children with $\mathrm{AD}$ showed less $\mathrm{AJA}$ and not overall less joint attention, although both groups had the same age and developmental level. If AJA is interpreted as the more socially joint attention behaviors (due to the related social awareness needed for these behaviors), children with autism may show more deficits in this social awareness domain than children with MR. Because the two groups did not differ on BJA we suggest that it is not just the basic joint attention skills in children with autism that are delayed or disturbed. Rather, the higher level of 'understanding the intention of another person' may show deficits. This deficit in 'social understanding' (and not low developmental level per se) may contribute to the deficits in AJA that are found in children with ASD. This interpretation is in line with the findings of Dawson et al. (2004), but also with the deficits that children with autism show during Theory of Mind tasks (Happe and Frith 1996) at an older age. More research is needed to test this hypothesis.

\section{Joint Attention and Security of Attachment}

Joint attention skills in typically developing children start developing during the first year of life. In the first year children spend most of their time with the mother. Joint attention may be triggered more often in a securely attached dyad than in insecure dyads. This 'practice' of joint attention skills might be reflected in the number of joint attention behaviors towards other people. Indeed in our study it was found that children with secure attachment relationships displayed more BJA and AJA compared to children without a secure attachment relationship. However, within the clinical groups, no differences between children with and without secure attachment were detected. After controlling for developmental level and autistic symptoms, no effect of attachment security was found.

Thus, secure attachment appears to predict the development of joint attention behaviors in typically developing children whereas in clinical groups no association between attachment security and joint attention was detected. This might be due to the limited cognitive abilities of atypically developing children. From a transactional perspective both parents and children contribute to the development of joint attention. Secure attachment may improve the quality of interactions between the child and the parent, which in turn may stimulate joint attention, but the limited cognitive abilities of the atypically developing child may restrict the child's eventual level of social interactions and social skills. Although the quality of interaction may be higher in securely attached children with cognitive impairments, these cognitive impairments may eventually impose limits on the development of joint attention skills. Notably, however, our findings are preliminary, due to the small numbers of children with a secure attachment relationship in the clinical groups.

\section{Joint Attention and Disorganized Attachment}

Disorganized attachment is considered to be the most anxious type of attachment, and it is associated with elevated risk for psychopathology (Carlson 1998; Van IJzendoorn et al. 1999). Disorganized attachment may affect the development of joint attention skills. In our study we indeed found that children with disorganized attachment showed less BJA and AJA. Also in our clinical group and in our group of children with ASD children with disorganized attachment showed less BJA compared to children without disorganized attachment. However, after controlling for developmental level and autistic symptoms, disorganized attachment did not predict BJA and AJA in the clinical group. It should be noted that our test of the hypothesis concerning the association between attachment and joint attention was of the most severe kind, in the sense that we controlled for various pertinent factors in a sample of clinical subjects leaving only part of the variance to be explained by attachment. The absence of the expected association, therefore, should not be interpreted as precluding the influence of attachment relationships on joint attention skills in non-clinical populations (Ainsworth 1992).

\section{Joint Attention, Attachment and Autism}

In the study of Claussen et al. (2002) it was already described that toddlers with a classification of attachment disorganization initiated less joint attention compared to secure attached toddlers. They suggested that a disturbance in the tendency to initiate JA may be indicative of early social-cognitive and social-emotional disturbance in chil- 
dren with a disorganized attachment relationship. Children with autism do have problems in these developmental domains regardless of their attachment relationship. It might be that children with autism with a secure attachment relationship are capable of developing somewhat better social-cognitive and social-emotional skills, although the impact of the attachment relationship may not be large enough to overrule the effects of the cognitive disturbances related to the autistic disorder. Children with autism may also feel less rewarded during the joint attention interactions because of their limited cognitive abilities to process information involved in the parental feedback on initiated joint attention episodes (Corkum and Moore 1998). Even securely attached children with ASD might find the joint attention interactions with their attachment figures less rewarding, and thus feel less stimulated to show more or higher levels of joint attention interactions.

\section{Limitations}

Although our study is one of the first studies on joint attention and attachment in children with ASD at this young age, more research in larger samples is needed to understand the interplay of clinical status, developmental level, attachment, and autistic symptoms on joint attention. The numbers of the children in the various clinical groups were small, in particular when attachment classifications were taken into account. To examine the influence of security and disorganization of attachment larger clinical and non-clinical groups are necessary.

All joint attention behaviors were recorded during tasks. During these tasks the child was stimulated to show joint attention behavior. The children's behaviors in these experimental settings may deviate from joint attention behaviors that are expressed in 'normal' circumstances. The ability of the child to perform the tasks might interfere with their joint attention during those tasks. To analyze the 'daily life' joint attention behaviors of children with clinical disorders, these children should be observed in their own environment, without experimental interference.

Furthermore, parental stimulation of the child's joint attention needs to be investigated. Children with autism may show overall deficits in joint attention behaviors, and they may show these problems also during joint attention on request, but research on responding and taking initiative in joint attention is scarce.

\section{Conclusion}

This study is the first investigation of joint attention and attachment in 2-year old children with autism and other clinical problems. Taken together, we found that developmental delays are related to less joint attention. Furthermore, already at the age of 2 years, children with more autistic symptoms showed less joint attention, even after controlling for developmental level. We conclude that children with autistic spectrum disorder suffer from lower levels of joint attention skills already at an early stage in their life.

The identification of autism-specific impairments in joint attention at this early age may have important clinical implications. Intervention programs may focus on the development of joint attention in order to try to improve the ability of these children to engage in this type of interaction. Improvement of joint attention skills may contribute to the development of language and social skills in children with autism, since joint attention skills are pivotal in socio-emotional and cognitive development.

Acknowledgements We like to thank the parents and children for their participation in this research. Marian J. Bakermans-Kranenburg and Marinus $H$. van IJzendoorn were supported by research grants from the Netherlands Organization for Scientific Research (MJBK: VIDI grant no. 452-04-306; MHvIJ: NWO SPINOZA prize).

\section{References}

Adrien, J. L., Lenoir, P., Martineau, J., Perrot, A., Hameury, L., Larmande, C., et al. (1993). Blind ratings of early symptoms of autism based upon family home movies. Journal of the American Academy of Child and Adolescent Psychiatry, 32, 617-626.

Ainsworth, M. D. (1992). Social referencing and attachment theory. In S. Feinman (Ed.), Social referencing and the social construction of reality in infancy (pp. 349-367). New York: Plenum.

Ainsworth, M. D. S., Blehar, M. C., Waters, M. C., \& Wall, S. (1978). Patterns of attachment. A psychological study of the strange situation. Hillsdale, N.J.: Erlbaum.

Arbuckle, J. L., \& Wothke, W. (1999). AMOS 4.0 user's guide (computer software manual).Chicago: Smallwaters.

Bakeman, R., \& Adamson, L. B. (1984). Coordinating attention to people and objects in mother-infant and peer-infant interaction. Child Development, 55, 1278-1289.

Baranek, G. T. (1999). Autism during infancy: A retrospective video analysis of sensory-motor and social behaviors at 9-12 months of age. Journal of Autism and Developmental Disorders, 29, 213-224.

Bretherton, I., McNew, S., \& Beegly-Smith, M. (1981). Early person knowledge as expressed in gestural and verbal communication; When do infants acquire a 'theory of mind'? In M. E. Lamb \& L. R. Sherrod (Eds.), Infant social cognition (pp. 333-373). Hillsdale, N.J.: Erlbaum.

Bruner, J. (1995). From joint attention to the meeting of minds: An introduction. In C. Moore \& P. J. Dunham (Eds.), Joint attention: Its origins and role in development (pp. 1-28). Hillsdale, NJ: Erlbaum.

Buitelaar, J. K., Van Engeland, H., De Kogel, K. H., De Vries, H., \& Van Hooff, J. A. R. A. M. (1991). Differences in the structure of social-behavior of autistic-children and non-autistic retarded controls. Journal of Child Psychology and Psychiatry, 32, 995-1015.

Campos, J. J. (1983). The importance of affective communication in social referencing: A commentary on Feinman. Merrill-Palmer Quarterly, 29, 83-87.

Carlson, E. A. (1998). A prospective longitudinal study of attachment disorganization/disorientation. Child Development, 69, 1107-1128. 
Carpenter, M., Pennington, B. F., \& Rogers, S. J. (2002). Interrelations among social-cognitive skills in young children with autism. Journal of Autism and Developmental Disorders, 32, 91-106.

Charman, T. (1997). The relationship between joint attention and pretend play in autism. Development and Psychopathology, 9, 1-16.

Charman, T. (2003). Why is joint attention a pivotal skill in autism? Philosophical Transactions of the Royal Society of London. Series B, Biological Sciences, 358, 315-324.

Claussen, A. H., Mundy, P. C., Mallik, S. A., \& Willoughby, J. C. (2002). Joint attention and disorganized attachment status in infants at risk. Development and Psychopathology, 14, 279-291.

Corkum, V., \& Moore, C. (1998). The origins of joint attention. Developmental Psychology, 34, 28-38.

Curcio, F. (1978). Sensorimotor functioning and communication in mute autistic children. Journal of Autism and Childhood Schizophrenia, 8, 281-292.

Dawson, G., Meltzoff, A. N., Osterling, J., Rinaldi, J., \& Brown, E. (1998). Children with autism fail to orient to naturally occurring social stimuli. Journal of Autism and Developmental Disorders, 28, 479-486.

Dawson, G., Toth, K., Abbott, R., Osterling, J., Munson, J., Estes, A., et al. (2004). Early social attention impairments in autism: Social orienting, joint attention, and attention to distress. Developmental Psychology, 40, 271-283.

De Wolff, M., \& van IJzendoorn, M. H. (1997). Sensitivity and attachment: A meta-analysis on parental antecedents of infant attachment. Child Development, 68, 571-591.

Dietz, C., Swinkels, S. H. N., Daalen van E., Engeland van H., \& Buitelaar, J. K. (2006). Screening for autistic spectrum disorders in children aged 14 to 15 months. II: Population screening with the Early Screening of Autistic Traits (ESAT). Design and general findings. Journal of Autism and Developmental Disorders, 36, 713-722.

DiLavore, P. C., Lord, C., \& Rutter, M. (2000). The pre-linguistic autism diagnostic observation schedule. Journal of Autism and Developmental Disorders, 25, 355-379.

Emde, R. N. (1992). Social referencing research. In S. Feinman (Ed.), Social referencing and the social construction of reality in infancy (pp. 79-94). New York: Plenum.

Fearon, P. R. M., \& Belsky, J. (2004). Attachment and Attention: Protection in relation to gender and cumulative social-contextual adversity. Child Development, 75, 1677-1693.

Feinman, S., \& Lewis, M. (1983). Social referencing at ten months: A second-order effect on infants' responses to strangers. Child Development, 54, 878-887.

Flanagan, P. J., Coppa, D. F., Riggs, S. G., \& Alario, A. J. (1994). Communication behaviors of infants of teen-mothers-An exploratory study. Journal of Adolescent Health, 15, 169-175.

Fombonne, E., Heavey, L., Smeeth, L., Rodrigues, L. C., Cook, C., Smith, P. G., et al. (2004). Validation of the diagnosis of autism in general practitioners records. BMC Public Health, 4(1), 5.

Goldsmith, D. F., \& Rogoff, B. (1997). Mothers' and toddlers' coordinated joint focus of attention: Variations with maternal dysphoric symptoms. Developmental Psychology, 33, 113-119.

Happe, F., \& Frith, U. (1996). Theory of mind and social impairment in children with conduct disorder. British Journal of Developmental Psychology, 14, 385-398.

Hesse, E., \& Main, M. (2006). Frightened, threatening, and dissociative (FR) parental behavior as related to infant D attachment in low-risk samples: Description, discussion and interpretations. Development and Psychopathology, 18, 309-343.

Hobson, R. P. (1993). Autism and the development of mind. London: Erlbaum.

Hutt, C., \& Ounsted, C. (1966). Biological significance of gaze aversion with particular reference to syndrome of infantile autism. Behavioral Science, 11, 346-356.

Kasari, C., Sigman, M., \& Yirmiya, N. (1993). Focused and social attention of autistic-children in interactions with familiar and unfamiliar adults - A comparison of autistic, mentally-retarded, and normal-children. Development and Psychopathology, 5, 403-414.

Leekam, S. R., Lopez, B., \& Moore, C. (2000). Attention and joint attention in preschool children with autism. Developmental Psychology, 36, 261-273.

Lewy, A. L., \& Dawson, G. (1992). Social stimulation and joint attention in young autistic-children. Journal of Abnormal Child Psychology, 20, 555-566.

Lord, C., Leventhal, B. L., \& Cook, E. H. (2001). Quantifying the phenotype in autism spectrum disorders. American Journal of Medical Genetics, 105, 36-38.

Lord, C., Rutter, M., \& Le Couteur, A. (1994). Autism diagnostic interview-Revised: A revised version of a diagnostic interview for caregivers of individuals with possible pervasive developmental disorders. Journal of Autism and Developmental Disorders, 24, 659-685.

Loveland, K. A., \& Landry, S. H. (1986). Joint attention and language in autism and developmental language delay. Journal of Autism and Developmental Disorders, 16, 335-349.

Main, M. (1983). Exploration, play, and cognitive functioning related mother-infant attachment. Infant Behavior and Development, 6, $167-174$.

Main, M., \& Solomon, J. (1990). Procedures for identifying infants as disorganized/disoriented during the Ainsworth strange situation. In M. T. Greenberg, D. Cicchetti, \& E. M. Cummings (Eds.), Attachment in preschool years: Theory, research and intervention (pp. 121-160). Chicago: University of Chicago Press.

McEvoy, R. E., Rogers, S. J., \& Pennington, B. F. (1993). Executive function and social communication deficits in young autistic-children. Journal of Child Psychology and Psychiatry, $34,563-578$

Meltzoff, A. N. (1988). Infant imitation and memory-9-month-olds in immediate and deferred tests. Child Development, 59, 217-225.

Morales, M., Mundy, P., Delgado, C. E. F., Yale, M., Messenger, D., Neal, R., et al. (2000). Responding to joint attention across the 6trough 24 month age period and early language acquisition. Journal of Applied Developmental Psychology, 21, 283-298.

Moss, E., St.Laurent, D., \& Parent, S. (1999). Disorganized attachment and developmental risk at school age. In J. Solomon \& C. George (Eds.), Attachment disorganization (pp. 160-186). New York: Guilford.

Mullen, E. M. (1995). Mullen scales of early learning. Circle Pines, $\mathrm{MN}$ : AGS

Mundy, P., \& Gomes, A. (1997). A skills approach to early language development: Lessons learned from research and research on developmental disabilities. In L. B. Adamson \& M. A. Romsky (Eds.), Communication and language acquisition: Discoveries from atypical development (pp. 107-139). Baltimore: Brookes.

Mundy, P., Sigman, M., \& Kasari, C. (1990). A longitudinal-study of joint attention and language-development in autistic-children. Journal of Autism and Developmental Disorders, 20, 115-128.

Mundy, P., Sigman, M., Ungerer, J., \& Sherman, T. (1986). Defining the social deficits of autism-The contribution of nonverbalcommunication measures. Journal of Child Psychology and Psychiatry, 27, 657-669.

Naber, F. B. A., Swinkels, S. H. N., Buitelaar, J. K., Dietz, C., Van Daalen, E., Bakermans-Kranenburg, M. J., et al. (2007). Attachment in toddlers with autism and other developmental disorders. Journal of Autism and Developmental Disorders (in press).

Noldus, L. P. J. J. (1991). The observer-A software system for collection and analysis of observational data. Behavior Research Methods, Instruments, \& Computers, 23, 415-429.

Osterling, J., \& Dawson, G. (1994). Early recognition of children with autism-A study of 1st birthday home videotapes. Journal of Autism and Developmental Disorders, 24, 247-257. 
Pedersen, J., Livoir-Petersen, M. F., \& Schelde, J. T. M. (1989). An ethological approach to autism-An analysis of visual behavior and interpersonal contact in a child versus adult interaction. Acta Psychiatrica Scandinavica, 80, 346-355.

Phillips, W., Gomez, J. C., Baron-Cohen, S., Laa, V., \& Riviere, A. (1995). Treating people as objects, agents, or "subjects": How young children with and without autism make requests. Journal of Child Psychology and Psychiatry, 36, 1383-1398.

Raver, C. C., \& Leadbeater, B. J. (1995). Factors influencing joint attention between socio-economically disadvantaged adolescent mothers and their infants. In C. Moore \& P. J. Dunham (Eds.), Joint attention: It's origins and role in development (pp. 251272). Hillsdale, N.J.: Earlbaum.

Richter, J. E., Waters, E., \& Vaughn, B. E. (1988). Empirical classification of infant-mother relationships from interactive behavior and crying during reunion. Child Development, 59, $512-522$.

Ruff, H. A., \& Rothbart, M. K. (1996). Attention in early development. New York: Oxford University Press.

Rutgers, A. H., van IJzendoorn, M. H., Bakermans-Kranenburg, M. J., \& Berkelaer-Onnes, I. A. (2004). Autism and attachment: A meta-analytic review. Journal of Child Psychology and Psychiatry, 45, 1123-1134.

Scholmerich, A., Lamb, M. E., Leyendecker, B., \& Fracasso, M. P. (1997). Mother-infant teaching interactions and attachment security in Euro-American and Central-American immigrant families. Infant Behavior \& Development, 20, 165-174.

Shafer, J., \& Graham, J. W. (2002). Missing data: Our view of state of the art. Psychological methods, 7, 147-177.

Sigman, M., Dijamco, A., Gratier, M., \& Rozga, A. (2004). Early detection of core deficits in autism. Journal of Mental Retardation and Developmental Disabilities Research Reviews, 10, 221-223.

Solomon, J., \& George, C. (1999). Attachment disorganization. New York: Guilford.

Sparrow, S. S., Balla, D. A., \& Ciccetti, D. V. (1997). Vineland socialemotional early childhood scales: Manual. Circle Pines, MN: AGS Service.

Stern, D. (1985). The interpersonal world of the infant. New York: Basic Books.

Stone, W. L., Lee, E. B., Ashford, L., Brissie, J., Hepburn, S. L., Coonrod, E., et al. (2002). Can autism be diagnosed accurately in children under 3 years? Journal of Child Psychology and Psychiatry and Allied Disciplines, 40, 219-226.

Swinkels, S. H. N., Dietz, C., van Daalen, E., Kerkhof, I., van Engeland, H., \& Buitelaar, J. K. (2006). Screening for autistic spectrum disorders in children aged 14 to 15 months. I. The development of the early screening of autistic traits questionnaire. Journal of Autism and Developmental Disorders, 36, 723-732.
Tabachnick, B. G., \& Fidell, L. S. (2001). Using multivariate statistics, international students edition (4th ed.). New York: Allyn and Bacon.

Tager-Flusberg, H. (2000). Understanding the language and communicative impairments in autism. International Review of Research on Mental Retardation, 23, 185-205.

Thompson, R. A. (1999). Early attachment and later development. In J. Cassidy \& P. Shaver (Eds.), Handbook of attachment: Theory, research and clinical applications (pp. 265-286). New York: Guilford.

Tiegerman, E., \& Primavera, L. H. (1984). Imitating the autistic-childFacilitating communicative gaze behavior. Journal of Autism and Developmental Disorders, 14, 27-38.

Tomasello, M. (1995). Joint attention as social cognition. In C. Moore \& P. J. Dunham (Eds.), Joint attention; its origins and role in development (pp. 103-130). Hillsdale, NJ: Erlbaum.

Van Engeland, H., Bodnar, F. A., \& Bolhuis, G. (1985). Some qualitative aspects of the social-behavior of autistic-children - an ethological approach. Journal of Child Psychology and Psychiatry, 26, 879-893.

van IJzendoorn, M. H., \& Kroonenberg, P. M. (1990). Cross-cultural consistency of coding the strange situation. Infant Behavior and Development, 13, 469-485.

van IJzendoorn, M. H., Schuengel, C., \& Bakermans-Kranenburg, M. J. (1999). Disorganized attachment in early childhood: Metaanalysis of precursors, concomitants, and sequelae. Development and Psychopathology, 11, 225-249.

Werner, E., Dawson, G., Osterling, J., \& Dinno, N. (2000). Brief report: Recognition of autism spectrum disorder before one year of age: A retrospective study based on home videotapes. Journal of Autism and Developmental Disorders, 30, 157-162.

Wetherby, A. M., \& Prutting, C. A. (1984). Profiles of communicative and cognitive-social abilities in autistic children. Journal of Speech and Hearing Research, 27, 364-377.

Willemsen-Swinkels, S. H. N., Bakermans-Kranenburg, M. J., Buitelaar, J. K., van IJzendoorn, M. H., \& van Engeland, H. (2000). Insecure and disorganized attachment in children with pervasive developmental disorder: Relationship with social interaction and heart rate. Journal of Child Psychology and Psychiatry and Allied Disciplines, 41(6), 759-767.

Willemsen-Swinkels, S. H. N., Buitelaar, J. K., Weijnen, F. G., \& Van Engeland, H. (1998). Timing of social gaze behavior in children with a pervasive developmental disorder. Journal of Autism and Developmental Disorders, 28, 199-210.

Wothke, W. (2000). Longitudinal and multi-group modeling with missing data. In T. D. Little, K. U. Schnabel, \& J. Baumert (Eds.), In Modeling longitudinal and multigroup data: Practival issues, applied approaches, and specific examples (pp. 219-240). Hillsdale, N.J.: Erlbaum. 